\title{
Synchrotron sources accelerate
}

\author{
New synchrotron sources are being commissioned and built around the globe, with an emphasis on \\ developing countries. Given the obvious benefits, the trend is encouraging.
}

Synchrotron radiation - an electromagnetic radiation emitted by electrons as they are caused to change direction by magnets while circulating in storage rings at nearly the speed of light - has revolutionized basic and applied research in many scientific and technological disciplines. This radiation can be a million to a billion times more intense than that produced by more conventional sources, such as X-ray tubes.

According to Lightsources.org, there are 47 synchrotron radiation research facilities based on electron storage rings (some with more than one ring) in 23 countries currently in operation, under construction or being planned. The recent new sources are the Taiwan Photon Source (TPS), Solaris in Poland, Sirius in Brazil and the Synchrotron-light for Experimental Science and Applications in the Middle East (SESAME) in Jordan.

The construction and commissioning of the TPS was successfully completed in December 2014 by the National Synchrotron Radiation Research Center of Taiwan (see also the News \& Views on page 292). The design of the TPS, a $3 \mathrm{GeV}$ facility measuring $518 \mathrm{~m}$ in circumference, features small emittance, large beam current, and high brilliance, stability and reliability. Solaris - the first Polish synchrotron radiation facility, with a very close cooperation with the MAX IV project in Lund, Sweden - is scheduled for completion in 2015, whereas Sirius, scheduled to start commissioning in 2018 and to be opened to users in 2019, is a state-of-theart fourth-generation machine built by the Brazilian Synchrotron Light Laboratory (LNLS). The SESAME is constructing the first major international research centre in the Middle East as a cooperative venture by the scientists and governments of nine countries in the region, under the umbrella of UNESCO. The $2.5 \mathrm{GeV}$ facility measuring $130 \mathrm{~m}$ in circumference is expected to operate fully in late 2016 or early 2017.

Following the completion of these new facilities, Africa will become the only habitable continent that is without a synchrotron source. Limited mostly by distance and travel costs, dozens of African scientists currently perform experiments at facilities in Europe and elsewhere. A light source in Africa would enable thousands of African scientists and engineers to gain access to this superb

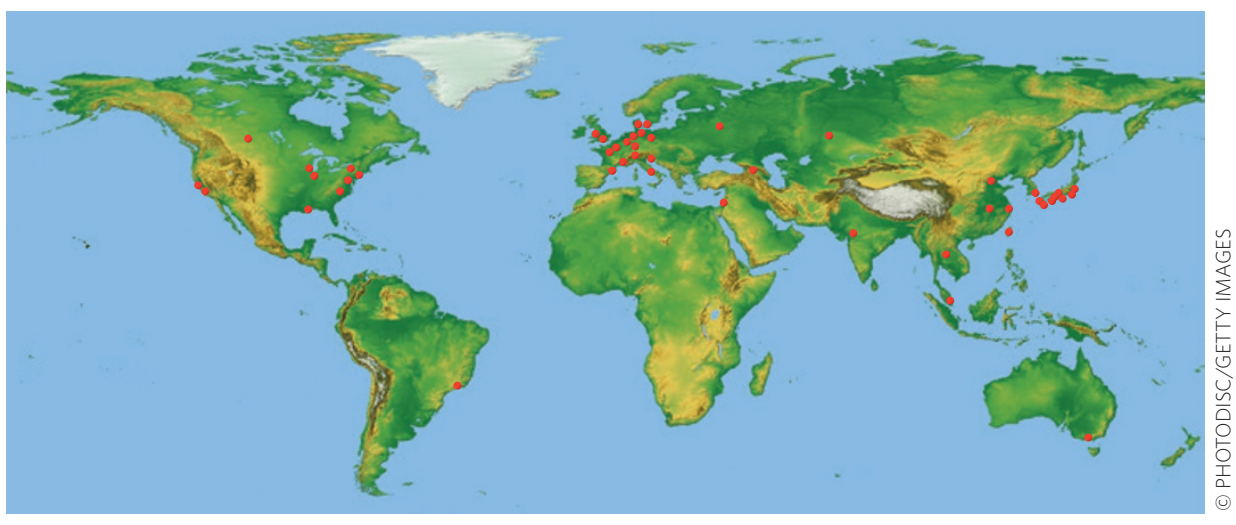

Locations of synchrotron light sources in the world. Data taken from Lightsources.org.

scientific and technological tool, and help them to be competitive socially, politically and economically in the years to come.

"The creation of synchrotron facilities will help world-class basic and applied research, train graduate students without sending them abroad, attract scientists conducting research abroad to return, address regional biomedical and environmental issues, and promote the development of high-tech industry," said Herman Winick from Stanford University and the SLAC National Accelerator Laboratory in California. "There will be less competition for beam time at foreign facilities, most of which are oversubscribed," he stressed.

The call for an African Light Source (ALS) is pressing, resembling that of SESAME, which was created 'bottom-up' by scientists who persuaded their governments to join. "The need for an international synchrotron source in the Middle East, which SESAME will satisfy, was recognized by eminent scientists more than thirty years ago," said Clarissa Formosa-Gauci, a representative of UNESCO's Division of Science Policy and Capacity-Building. It was not until 1999 that an international interim council was formed after a meeting of UNESCO in Paris, following the example of CERN, which was also founded under the umbrella of UNESCO.

When asked if UNESCO would play a similar role as a facilitator for the ALS, Formosa-Gauci said, "UNESCO welcomes the creation of synchrotron sources elsewhere, particularly in developing countries, and it is ready to offer its experience to help those countries wishing to do so."
Triggered by the example of projects in Brazil, Taiwan and particularly Jordan, an interim steering committee has recently been launched. According to Winick, who is in the committee, "the committee is currently in the first phases of convincing African scientists, policy makers and stakeholders of the great value of this project." There are of course obstacles, but "none that cannot be overcome," said Winick with confidence.

"I am urging a competition for the host country. Following the example of SESAME, the country offering the most will be successful. I expect that at least six countries will join, perhaps ten or more," said Winick.

"Accelerator technology is still evolving. $3 \mathrm{GeV}$ seems to be the optimal electron energy. A circumference of $500 \mathrm{~m}$ or more is desirable, but a smaller facility, at a lower price, should also be considered. A study should be made by the African scientists to determine the best design," said Winick about the scale of the ALS. "It would take a decade or more for a project similar to SESAME to be facilitated in Africa," he added.

"The scientific community using synchrotron sources is growing faster than the number of beamlines. This will continue. I hope that the USA, as one of the leaders in synchrotron radiation sources and science, will join on this," urged Winick.

Access to a nearby synchrotron source brings many benefits, not only to developing countries but also to technologically advanced countries. The active involvement of scientists and the full support of UNESCO and governments are vital. 